\title{
Communication \\ Constitutive Changes in Nutrients and Phytochemicals in Kernels of Aluminium-Tolerant Maize (Zea mays L.)
}

\author{
Sofia Ortiz-Islas, Sergio Serna-Saldivar and Silverio García-Lara *(D)
}

check for

updates

Citation: Ortiz-Islas, S.;

Serna-Saldivar, S.; García-Lara, S. Constitutive Changes in Nutrients and Phytochemicals in Kernels of Aluminium-Tolerant Maize

(Zea mays L.). Crops 2022, 2, 14-22. https://doi.org/10.3390/ crops2010002

Academic Editor:

Antonella Pasqualone

Received: 16 November 2021

Accepted: 21 December 2021

Published: 25 January 2022

Publisher's Note: MDPI stays neutral with regard to jurisdictional claims in published maps and institutional affiliations.

Copyright: (c) 2022 by the authors Licensee MDPI, Basel, Switzerland. This article is an open access article distributed under the terms and conditions of the Creative Commons Attribution (CC BY) license (https:/ / creativecommons.org/licenses/by/ $4.0 /)$.
Tecnológico de Monterrey, EIC, Eugenio Garza Sada 2501, Monterrey 64849, Mexico; sofiort@hotmail.com (S.O.-I.); sserna@tec.mx (S.S.-S.)

* Correspondence: sgarcialara@tec.mx; Tel.: +52-81-83582400

\begin{abstract}
Maize (Zea mays L.) is among the three most important food crops worldwide. Maize growth is affected by high aluminium content in acid soils, which constitute nearly $50 \%$ of the world's cultivable area. Therefore, the cultivation of aluminium-tolerant maize hybrids could be a healthier alternative and an attractive food source in these regions. In this regard, to produce hybrids kernels, 16 inbred lines aluminium-tolerant (Al-T) and aluminium-susceptible (Al-S) maize were screened for their constitutive patterns of selected nutrients and phytochemicals. Proximate analysis, free phenolic acids (FPA) and cell wall-bound phenolic acids (CPA) contents, as well as antioxidant capacity (AOX) were assayed in the anatomical kernel parts (pericarp, endosperm, and germ). Kernels of Al-T maize contained significantly higher germ protein, oil, and fibre $(2.9,3.0$, and $0.5 \%$, respectively) than Al-S kernels $(1.9,1.8$, and $0.3 \%$, respectively). Importantly, the nutraceutical contents in terms of pericarp FPA and germ CPA were significantly higher in kernels belonging to Al-T maize (92 mg and $140 \mathrm{mg}$ EGA/100 g). The highest AOX was observed in germ CPA of Al-T kernels (9.0 mmol TE/100 g). The results herein indicate that Al-tolerance mechanisms induce positive changes in the nutrients and phytochemicals; this implies that the hybrids generated using Al-T maize inbred lines could emerge as an attractive source of nutrients and phytochemicals in farming regions containing acid soils.
\end{abstract}

Keywords: Zea mays; phenolic acids; aluminium-tolerant; nutrients; phytochemicals

\section{Introduction}

Maize (Zea mays L.) is among the most important food crops worldwide [1]. Maize, rice, and wheat provide at least $60 \%$ calories and $50 \%$ protein to consumers in developing countries [2]. Essentially, maize production and yield should increase constantly in order to satisfy the increasing demand for food, given the expected population growth [3]. Unfortunately, maize production is limited in developing countries of America, Asia, and Africa due to the presence of large extensions of acidic soils $(\mathrm{pH}<5.5)$ that represent around $50 \%$ of the world's cultivable area [3]. These acidic soils constitute about $30 \%$ of the total land in the world and 70\% of potentially arable land in the world [4] (Panda et al., 2009).

Aluminium (Al) toxicity is the primary factor limiting plant growth in acidic soils and is mainly responsible for the reduction in crop yields [5,6]. This toxicity reduces root water and nutrient uptake due to both root damage and growth inhibition [7,8]. Previous studies have reported that maize has an important heritable tolerance to acidic soil stress $[9,10]$. In addition, the use of Al-tolerant (Al-T) maize genotypes could enhance productivity in a sustainable system by minimising root damage in acidic soils [6,11].

The tolerance of maize genotypes to $\mathrm{Al}$ is a complex process that involves multiple genes and physiological mechanisms, which are still unclear [12]. The resistance mechanisms are also affected by fundamental plant and kernel composition in terms of macroand micronutrients. Therefore, the cultivation of aluminium-tolerant maize hybrids could be a healthier alternative and an attractive food source in these regions. This research was conducted to investigate the involvement of constitutive nutrients and phytochemicals 
associated with Al-tolerant maize kernel genotypes. In this regard, to produce hybrids kernels, 16 inbred lines aluminium-tolerant (Al-T) and aluminium-susceptible (Al-S) maize were screened for their constitutive patterns of selected nutrients and phytochemicals. Furthermore, a more detailed study was conducted using their dissected kernel tissues (pericarp, endosperm, and germ). These anatomical parts were compared in terms of proximate composition, free phenolic acids (FPA), cell wall-bound phenolic acids (CPA), and antioxidant capacity (AOX).

The practical implication of this research is that Al-tolerant inbred lines may produce hybrids that are capable of overcoming nutrient deficiencies when planted in acid soils. In addition, they could help in reducing the problem of food scarcity in the investigated areas and at the same time provide important nutrients and nutraceuticals for inhabitants of developing countries. As a preliminary study, we expect that in future studies a detailed evaluation of the effect of Al concentration on specific PA and its profile in maize kernels should be the main focus.

\section{Results}

\subsection{Morphological Parameters and Proximate Composition}

Significant changes in morphological of both Al-T and Al-S kernels were observed. In Al-T kernels, a difference of $61 \%$ in flotation index was observed in comparison with Al-S kernels (Table 1). In terms of the anatomical parts, an increment of $66 \%$ in germ quantity and a decrease of $6 \%$ in endosperm quantity were found in Al-T kernels when compared to Al-S kernels. Moreover, the kernel anatomical structures significantly differed between the two lines. The tolerant lines contained $66 \%$ more protein, $83 \%$ more oil and $67 \%$ more fibre in the germ (2.9\% vs. $1.9 \%$ protein; $3.0 \%$ vs. $1.8 \%$ oil; $0.5 \%$ vs. $0.3 \%$ fiber), as well as $7 \%$ less starch and $15 \%$ less fibre in the endosperm. In contrast, the pericarp structures of both Al-T and Al-S lines showed no significant difference in terms of proximal composition (Table 2). These results clearly indicate that tolerance to Al was related to changes in kernel anatomical proportions and compositions, particularly the nutrients associated with the endosperm and germ.

\subsection{Phytochemical Composition}

A similar trend was observed when the phenolic compounds and AOX of tolerant and susceptible inbred lines were compared. Significant differences in pericarp and germ FPA and CPA were observed. Total phenolic content and pericarp FPA of Al-T kernels were approximately 90\% higher (Figure 1A) than those of Al-S kernels (92 mg vs. $46 \mathrm{mg}$ EGA/100 g); Al-T kernels germ CPA were 26\% higher compared with Al-S kernels germ (Figure 1B) (140 mg vs. $122 \mathrm{mg}$ EGA/100 g). The significant differences found in phenolic compounds between Al-T and Al-S lines indicate that the mechanism of tolerance to Al could enhance the nutraceutical composition of the kernel, especially in terms of antioxidants.

\subsection{Antioxidant Activity}

The AOX of each genotype is depicted in Figure 2. Comparison between average AOX of Al-T and Al-S indicated similar AOX for free compounds in all the anatomical structures investigated with ranges between $1.2 \mathrm{mmol}$ to $5.3 \mathrm{mmol}$ of TE/100 g (Figure 2A). The same trend was observed when cell wall-bound compounds associated with both the pericarp and endosperm were compared (Figure 2B). In contrast, a significant difference in the germ AOX of cell wall-bound compounds (an increase of $23 \%$ in Al-T with 9.3 vs. 7.2 mmol TE/100 $\mathrm{g}$ of Al-S) was found (Figure 2B). These findings confirm that AOX may positively change due to $\mathrm{Al}$ tolerance mechanisms. Nevertheless, this result was only observed at the germ structure. 
Table 1. Comparison in main morphological and anatomical characteristics of selected maize inbred lines tolerant and susceptible to aluminum.

\begin{tabular}{|c|c|c|c|c|c|c|c|c|c|c|c|c|c|c|c|c|c|c|c|c|c|c|c|c|c|c|c|c|c|c|}
\hline \multirow{3}{*}{$\begin{array}{l}\text { Genotype } \\
\text { CLA161 }\end{array}$} & \multirow{3}{*}{$\begin{array}{c}\text { Type } \\
\mathrm{T}\end{array}$} & \multicolumn{8}{|c|}{ Morphological Properties } & \multicolumn{12}{|c|}{ Anatomical Proportions (\%) } & \multicolumn{9}{|c|}{ Kernel Dimensions (mm) } \\
\hline & & \multirow{2}{*}{$\begin{array}{l}\text { Color } \\
\text { YW }\end{array}$} & \multirow{2}{*}{$\begin{array}{l}\text { Tex } \\
1.2\end{array}$} & \multicolumn{3}{|c|}{ FI } & \multicolumn{3}{|c|}{$1000 \mathrm{~K}$} & \multicolumn{3}{|c|}{ Pericarp } & \multicolumn{3}{|c|}{ Endosperm } & \multicolumn{3}{|c|}{ Germ } & \multicolumn{3}{|c|}{ Tip } & \multicolumn{3}{|c|}{ Width } & \multicolumn{3}{|c|}{ Long } & \multicolumn{3}{|c|}{ Thickness } \\
\hline & & & & 35 & \pm & 5 & 192.8 & \pm & 0.2 & 5.5 & \pm & 0.2 & 78.3 & \pm & 0.1 & 13.9 & \pm & 0.3 & 2.2 & \pm & 0.1 & 7.9 & \pm & 0.5 & 7.7 & \pm & 0.3 & 4.4 & \pm & 0.4 \\
\hline CLA309 & $\mathrm{T}$ & YW & 0.5 & 0 & \pm & 0 & 195.7 & \pm & 1.4 & 7.6 & \pm & 0.2 & 77.5 & \pm & 1.1 & 11.7 & \pm & 0.9 & 3.1 & \pm & 0.4 & 7.4 & \pm & 0.4 & 8.5 & \pm & 0.4 & 4.2 & \pm & 0.4 \\
\hline CLA37 & $\mathrm{T}$ & YW & 2.3 & 10 & \pm & 2 & 229.0 & \pm & 0.3 & 5.4 & \pm & 0.1 & 79.8 & \pm & 0.6 & 11.7 & \pm & 0.3 & 3.0 & \pm & 0.3 & 7.8 & \pm & 0.2 & 9.4 & \pm & 0.6 & 4.4 & \pm & 0.3 \\
\hline CML-483 & $\mathrm{T}$ & $\mathrm{WH}$ & 2.7 & 0 & \pm & 0 & 289.9 & \pm & 6. & 4.2 & \pm & 0.0 & 84.6 & \pm & 0.3 & 9.2 & \pm & 0.1 & 2.0 & \pm & 0.3 & 8.8 & \pm & 0.2 & 9.1 & \pm & 0.3 & 4.8 & \pm & 0.1 \\
\hline CLA307 & $\mathrm{T}$ & YW & 2.2 & 20 & \pm & 2 & 229.2 & \pm & 8 & 5.7 & \pm & 0.0 & 83.2 & \pm & 0.3 & 9.4 & \pm & 0.4 & 1.7 & \pm & 0.3 & 8.8 & \pm & 0.2 & 8.5 & \pm & 0.4 & 4.8 & \pm & 0.4 \\
\hline CLA41 & $\mathrm{T}$ & YW & 2.6 & 65 & \pm & 5 & 195.2 & \pm & 1. & 5.7 & \pm & 0.1 & 82.8 & \pm & & 7.9 & \pm & 0.3 & 3.6 & \pm & 0.2 & 9.1 & \pm & .4 & 9.0 & \pm & .4 & 3.8 & \pm & 0.2 \\
\hline CLA44 & $\mathrm{T}$ & YW & 3.0 & 10 & \pm & 0 & 204.5 & \pm & & 5.9 & \pm & 0 & 80.4 & \pm & & 10.6 & \pm & 0 & 3.1 & & & 7.3 & \pm & & 7.9 & \pm & 4 & 5.0 & \pm & 0.5 \\
\hline CLA & $\mathrm{T}$ & $\mathrm{Y}$ & & 1 & \pm & 5 & 216 & \pm & & & \pm & & & & & & \pm & & & & & & \pm & & 9.4 & \pm & 2 & & \pm & .3 \\
\hline CLA84 & $\mathrm{T}$ & YW & 2.2 & 25 & \pm & 5 & 227.2 & \pm & & 5.8 & \pm & 0.2 & 81.4 & \pm & & 9.3 & \pm & 0.3 & 3.5 & \pm & & 8.9 & \pm & .3 & 10.6 & \pm & 0.5 & 4.3 & \pm & 0.4 \\
\hline DTPWC9 & S & WH & 3.4 & 15 & \pm & 5 & 234.8 & \pm & 2.4 & 3.9 & \pm & 0.1 & 83.5 & \pm & 0.1 & 9.9 & \pm & 0.2 & 2.8 & \pm & 0.2 & 8.1 & \pm & 0.3 & 8.5 & \pm & 0.3 & 5.0 & \pm & 0.5 \\
\hline LaPosta & S & $\mathrm{WH}$ & 2.5 & 60 & \pm & 5 & 263.7 & \pm & 3.5 & 5.9 & \pm & 0.1 & 84.2 & \pm & 0.9 & 6.6 & \pm & 0.4 & 3.3 & \pm & 0.7 & 8.7 & \pm & 0.4 & 10.6 & \pm & 0.2 & 4.7 & \pm & 0.3 \\
\hline CML311B & S & $\mathrm{WH}$ & 2.7 & 60 & \pm & 6 & 132.8 & \pm & 0.7 & 4.2 & \pm & 0.1 & 87.2 & \pm & 0.8 & 5.4 & \pm & 0.2 & 3.2 & \pm & 0.5 & 7.7 & \pm & 0.4 & 7.0 & \pm & 0.4 & 4.5 & \pm & 0.4 \\
\hline CLA35 & S & YW & 2.5 & 55 & \pm & 5 & 157.1 & \pm & 2.7 & 6.2 & \pm & 0.2 & 81.2 & \pm & 0.2 & 7.1 & \pm & 0.1 & 5.4 & \pm & 0.5 & 7.5 & \pm & 0.4 & 8.6 & \pm & 0.7 & 3.8 & \pm & 0.4 \\
\hline P390aC3 & S & YW & 2.1 & 0 & \pm & 0 & 309.0 & \pm & 5.2 & 5.2 & \pm & 0.2 & 85.4 & \pm & 0.4 & 6.3 & \pm & 0.4 & 3.2 & \pm & 1.0 & 9.0 & \pm & 0.2 & 9.9 & \pm & 0.1 & 4.8 & \pm & 0.5 \\
\hline DTPWC9 & S & $\mathrm{WH}$ & 2.3 & 60 & \pm & 5 & 186.8 & \pm & 2.7 & 4.5 & \pm & 0.2 & 90.1 & \pm & 0.6 & 4.9 & \pm & 0.4 & 0.5 & \pm & 0.2 & 8.1 & \pm & 0.7 & 9.3 & \pm & 0.2 & 3.8 & \pm & 0.1 \\
\hline Tukey-Test & & & ns & & $*$ & & ns & & & ns & & & $*$ & & & $*$ & & & ns & & & ns & & & ns & & & ns & & \\
\hline
\end{tabular}

Data represents the average of three replicates \pm standard derivation. Abbreviations: $\mathrm{T}=$ tolerant to aluminum, $\mathrm{S}=$ susceptible to aluminum, Tex $=$ texture of endosperm, FI $=$ Flotation Index, $1000 \mathrm{~K}=$ Thousand-kernel $(\mathrm{g})$ weight. * Significant difference at $p<0.05 ; \mathrm{ns}=$ non-significant. 
Table 2. Comparison proximal analysis by kernel structure of selected maize inbred lines tolerant and susceptible to aluminum.

\begin{tabular}{|c|c|c|c|c|c|c|c|c|c|c|c|c|c|c|c|c|c|c|c|c|c|}
\hline \multirow[t]{2}{*}{ Genotype } & \multirow[t]{2}{*}{ Type } & \multicolumn{4}{|c|}{ Protein (\%) } & \multicolumn{4}{|c|}{ Oil (\%) } & \multicolumn{4}{|c|}{ Starch (\%) } & \multicolumn{4}{|c|}{ Fiber (\%) } & \multicolumn{4}{|c|}{ Ash (\%) } \\
\hline & & Per & End & Ger & Tot & Per & End & Ger & Tot & Per & End & Ger & Tot & Per & End & Ger & Tot & Per & End & Ger & Tot \\
\hline CLA161 & $\mathrm{T}$ & 0.2 & 7.6 & 3.8 & 11.6 & 0.1 & 1.9 & 3.7 & 5.6 & 0.1 & 60.0 & 0.5 & 60.5 & 0.3 & 0.9 & 0.7 & 1.9 & 0.1 & 1.0 & 0.1 & 1.1 \\
\hline CLA309 & $\mathrm{T}$ & 0.2 & 8.7 & 2.6 & 11.6 & 0.1 & 2.0 & 2.7 & 4.7 & 0.1 & 57.6 & 2.2 & 59.8 & 0.5 & 1.0 & 0.4 & 1.9 & 0.1 & 0.9 & 0.1 & 1.1 \\
\hline CLA37 & $\mathrm{T}$ & 0.0 & 9.0 & 2.4 & 11.4 & 0.1 & 2.0 & 3.2 & 5.2 & 0.1 & 58.2 & 2.1 & 60.2 & 0.3 & 0.9 & 0.3 & 1.6 & 0.1 & 0.9 & 0.0 & 1.0 \\
\hline CML-483 & $\mathrm{T}$ & 0.0 & 9.1 & 2.5 & 11.6 & 0.0 & 1.8 & 2.6 & 4.5 & 0.0 & 61.5 & 0.6 & 62.2 & 0.3 & 0.9 & 0.5 & 1.7 & 0.1 & 1.0 & 0.0 & 1.1 \\
\hline CLA307 & $\mathrm{T}$ & 0.2 & 9.1 & 2.9 & 12.3 & 0.1 & 2.2 & 2.8 & 5.1 & 0.1 & 63.3 & 1.5 & 64.8 & 0.3 & 1.0 & 0.4 & 1.7 & 0.1 & 1.2 & 0.0 & 1.4 \\
\hline CLA41 & $\mathrm{T}$ & 0.1 & 11.3 & 2.3 & 13.6 & 0.1 & 1.9 & 1.8 & 3.6 & 0.1 & 62.0 & 1.5 & 63.4 & 0.4 & 1.6 & 0.4 & 2.4 & 0.1 & 1.3 & 0.1 & 1.4 \\
\hline CLA44 & $\mathrm{T}$ & 0.3 & 10.6 & 3.7 & 14.6 & 0.1 & 2.2 & 3.7 & 5.9 & 0.1 & 59.5 & 0.0 & 59.5 & 0.4 & 1.4 & 0.5 & 2.3 & 0.1 & 1.1 & 0.1 & 1.2 \\
\hline CLA18 & $\mathrm{T}$ & 0.1 & 9.5 & 1.9 & 11.6 & 0.1 & 2.0 & 2.2 & 4.2 & 0.1 & 58.9 & 1.6 & 60.5 & 0.2 & 1.3 & 0.3 & 1.8 & 0.1 & 1.0 & 0.0 & 1.1 \\
\hline CLA81 & $\mathrm{T}$ & 0.1 & 11.3 & 3.2 & 14.6 & 0.1 & 1.9 & 3.3 & 5.2 & 0.1 & 61.3 & 0.0 & 61.2 & 0.4 & 1.4 & 0.6 & 2.4 & 0.1 & 1.1 & 0.0 & 1.3 \\
\hline CLA84 & $\mathrm{T}$ & 0.1 & 10.7 & 3.2 & 14.0 & 0.1 & 2.8 & 3.5 & 6.3 & 0.1 & 60.9 & 0.0 & 61.0 & 0.5 & 1.3 & 0.6 & 2.3 & 0.1 & 1.1 & 0.1 & 1.3 \\
\hline DTPWC9 & $S$ & 0.1 & 6.6 & 2.2 & 9.0 & 0.1 & 1.8 & 2.6 & 4.4 & 0.1 & 61.5 & 1.9 & 63.5 & 0.2 & 1.3 & 0.3 & 1.7 & 0.1 & 1.0 & 0.1 & 1.1 \\
\hline LaPosta & $S$ & 0.1 & 10.7 & 2.1 & 12.9 & 0.1 & 2.3 & 1.9 & 4.3 & 0.1 & 62.7 & 0.2 & 62.9 & 0.4 & 1.3 & 0.4 & 2.1 & 0.1 & 1.2 & 0.1 & 1.3 \\
\hline CML311B & $\mathrm{S}$ & 0.2 & 11.8 & 1.5 & 13.4 & 0.0 & 2.1 & 1.3 & 3.4 & 0.0 & 62.5 & 1.7 & 64.2 & 0.3 & 1.4 & 0.3 & 2.0 & 0.1 & 1.2 & 0.0 & 1.4 \\
\hline CLA35 & S & 0.1 & 10.9 & 2.0 & 13.0 & 0.1 & 1.9 & 1.7 & 3.6 & 0.1 & 62.1 & 1.9 & 64.1 & 0.4 & 1.2 & 0.3 & 2.0 & 0.1 & 1.1 & 0.0 & 1.3 \\
\hline P390am & $\mathrm{S}$ & 0.1 & 12.2 & 1.8 & 14.2 & 0.1 & 2.0 & 1.6 & 3.6 & 0.1 & 61.6 & 0.9 & 62.5 & 0.4 & 1.5 & 0.3 & 2.1 & 0.1 & 1.2 & 0.0 & 1.4 \\
\hline DTPWC9 & $S$ & 0.2 & 9.1 & 1.6 & 10.9 & 0.1 & 2.0 & 1.4 & 3.4 & 0.1 & 70.5 & 0.3 & 70.7 & 0.3 & 1.4 & 0.3 & 2.0 & 0.1 & 1.4 & 0.1 & 1.5 \\
\hline Mean & S & 0.1 & 10.2 & 1.9 & 12.2 & 0.1 & 2.0 & 1.8 & 3.8 & 0.1 & 63.5 & 1.2 & 64.6 & 0.3 & 1.3 & 0.3 & 2.0 & 0.1 & 1.2 & 0.1 & 1.3 \\
\hline \multicolumn{2}{|c|}{ Tukey-Test } & ns & ns & $*$ & ns & ns & ns & $*$ & $*$ & ns & $*$ & ns & * & ns & $*$ & $*$ & ns & ns & ns & ns & ns \\
\hline
\end{tabular}

Data in percent $/$ structure represents the average of three replicates \pm standard derivation. Abbreviations: $\mathrm{T}=$ tolerant to aluminum, $\mathrm{S}=$ susceptible to aluminum, Per $=$ pericarp, End $=$ endosperm, Ger $=$ germ, Tot $=$ total percent. ${ }^{*}$ Significant difference at $p<0.05 ; \mathrm{ns}=$ non-significant. 
A

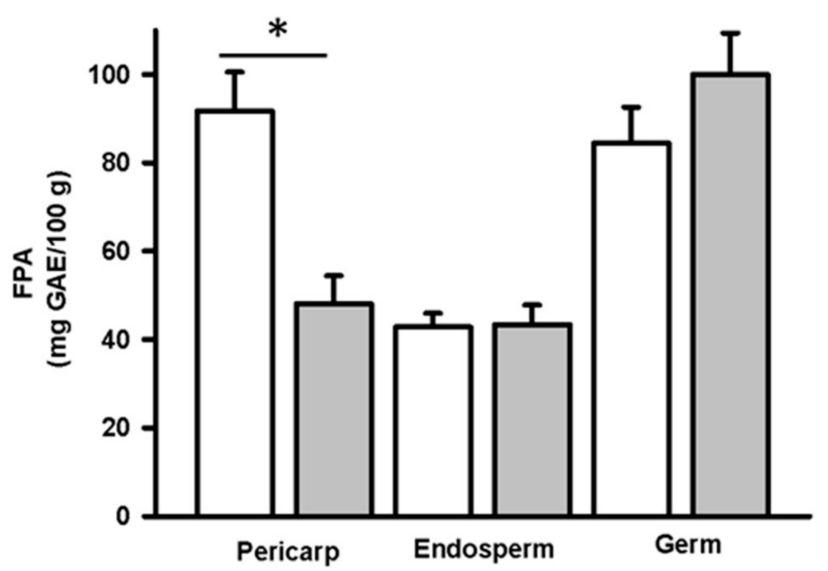

B

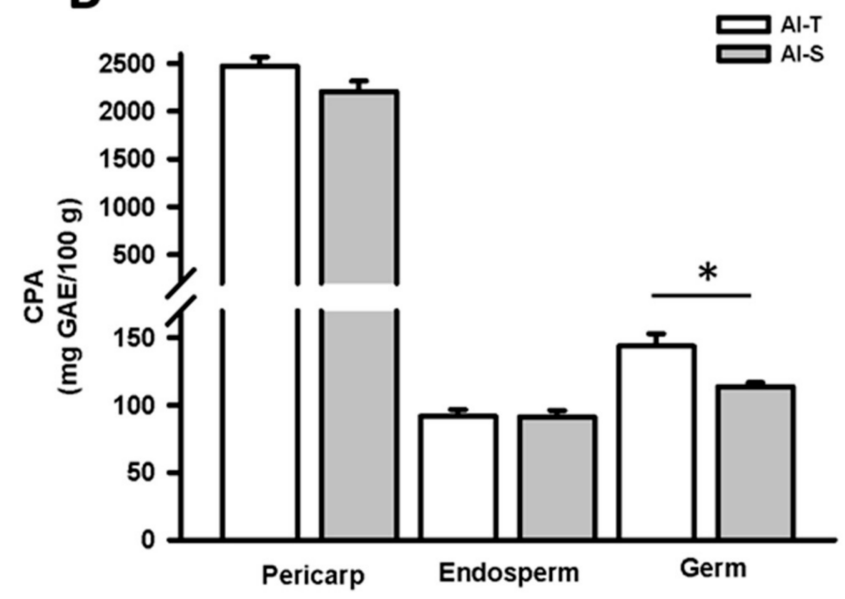

Figure 1. Phenolic acids content found in kernel structures of Al-tolerant (Al-T) and Al-susceptible (Al-S) maize inbred lines. Free phenolic acids (A) and cell wall-bound phenolic acids (B) content in pericarp, endosperm, and germ from Results are expressed as $\mathrm{mg}$ of gallic acid equivalents (GAE) in $100 \mathrm{~g}$. Data represents the mean of six genotypes plus the standard error of the mean. * Significant difference at $p<0.05$ by Tukey test comparison. Abbreviations: FPA $=$ Free phenolic acids, $\mathrm{CPA}=$ Cell wall-bound phenolic acids.

A

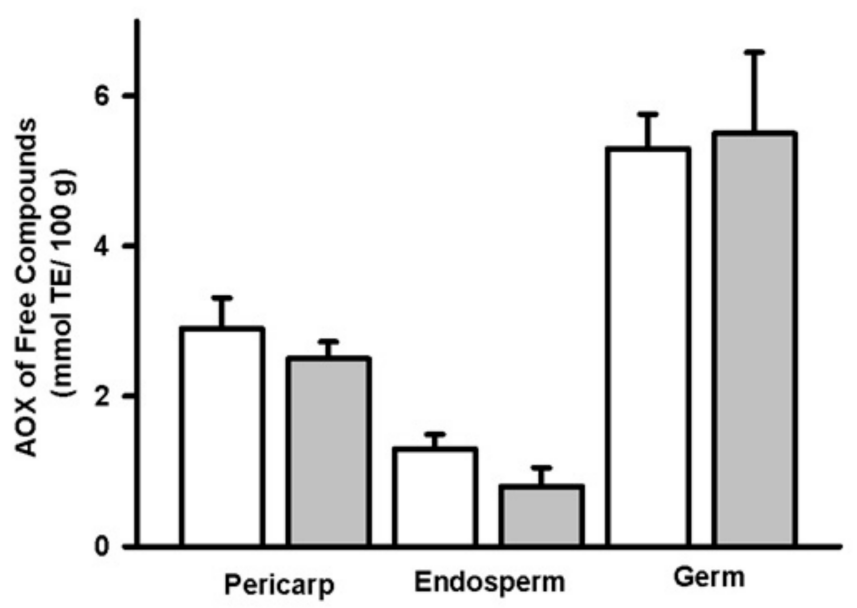

B

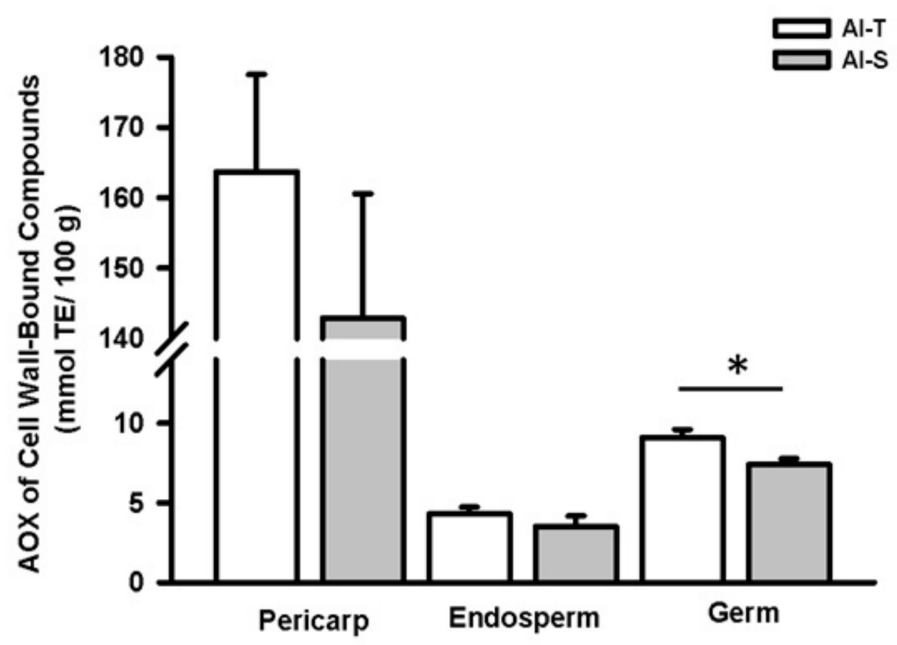

Figure 2. Antioxidant capacity of phenolic acids in kernel structures of Al-tolerant (Al-T) and Alsusceptible (Al-S) maize inbred lines. AOX of free (A) and cell wall-bound phenolic compounds (B) found in pericarp, endosperm and germ. Data represents the mean of six genotypes plus the standard error of the mean. * Significant difference at $p<0.05$ by Tukey test comparison. Abbreviations: $\mathrm{AOX}=$ Antioxidant capacity, $\mathrm{TE}=$ trolox equivalents.

\section{Discussion}

This study established a relationship between the Al tolerance of maize inbred lines and their nutrient and phytochemicals kernel composition. The different anatomical parts of Al-T kernels presented significant differences in these compounds when compared to their susceptible counterparts.

Total tissue analysis showed that the highest percent of kernel macronutrients, such as protein, oil, starch, and fibre, were found in the endosperm of both groups as this 
reserve tissue was the major fraction found in the kernel (83\%) [13]. The endosperm mainly contains starch $(87.6 \%)$, followed by protein and fibre [14]. However, it was observed that the endosperms of Al-tolerant kernels contained lower amounts of starch and fibre. In contrast, a previously reported individual analysis of kernel structures revealed that the germ of Al-tolerant kernels contained higher amounts of macronutrients [13,15]. The Al-T germ contained higher amounts of protein, oil, and fibre than that of the Al-S germ. The maize germ is principally used for oil extraction, and the partially defatted germ meal is mainly used as animal feed [2]. Furthermore, the germ is the maize kernel structure with the best amino acid profile and protein content [14]. Therefore, Al-T lines to produce hybrids could represent a good alternative for the production of human foods with higher protein content and quality.

A comparison of phenolic acid (PA) content of Al-T kernels and their susceptible counterparts indicated that the mechanism of resistance resulted in an enhancement of the phytochemicals of the kernel. The most notorious difference in PA between the two groups was found for pericarp FPA, where a 2-fold increment in concentration was observed in the Al-T kernels. In contrast, while a major PA content was observed in the CPA of both Al-T and Al-S kernels, only a significant difference in germ for CPA was observed. It has been shown that some Al-T plants can modify their production of PA [16,17]. This effect has principally been investigated in root tips exudates, where Al-binding compounds play an important role in $\mathrm{Al}$ detoxification [18]. In this context, an increase in flavonoid-type phenolic content of root exudates was attributed to $\mathrm{Al}$ tolerance in maize [19]. In other Al-T species, such as Polygonaceae, caffeic acid, catechol, and catechin are the principal PAs implicated in root Al detoxification [17]. Nevertheless, to the best of our knowledge, this is the first study in which significant differences in total PA due to the Al tolerance mechanism were found in mature maize kernels $[12,20]$. At the same time, the higher PA content can contribute to enhancing the nutraceutical potential, especially in terms of AOX and the prevention of oxidative stress.

The highest AOX was observed in the pericarp CPA of both Al-T and Al-S kernels. This higher AOX also coincided with the high CPA observed in both groups. Surprisingly, only the germ of Al-T kernels had a significant difference in the AOX of CPA. This finding corroborates the higher CPA content in the germ of Al-T kernels in comparison with their susceptible counterparts and establishes the $\mathrm{Al}$ tolerance-induced changes in the phytochemicals profile of kernels. It is known that $\mathrm{Al}$ stress induces the production of reactive oxygen species (ROS), which is efficiently controlled by the antioxidant defence systems of tolerant plants [20-22]. The first defense line against ROS is constituted by the enzymes superoxide dismutase and peroxidase, which use phenolic co-substrates [21]. At the same time, specific genes, such as ZmAT6, are activated in Al-T maize [23]. Recent proteomics studies of Al-T maize have shown the induction of complex transcriptome changes in the transcript levels for several genes, which were primarily related to cell wall structure and metabolism, oxidative stress response, membrane transporters, and organic acid metabolism [24]. Therefore, the increment in AOX and PA compounds in Al-T maize lines may be related to this mechanism. Although our study does not include enzymatic activity quantification or determination of other antioxidant species other than PA as previously reported in Al-susceptible maize lines [25], the novel AOX variation found in maize kernels due to $\mathrm{Al}$ tolerance has not been previously reported.

The results presented herein provide the basis for taking advantage of $\mathrm{Al}$ tolerance in maize lines to enhance the nutrient and phytochemical content of kernels. These findings would allow the exploitation of this tolerance mechanism in maize kernels lines not only to solve the agricultural problem of reduction in maize grain yield due to $\mathrm{Al}$ soil toxicity but also to improve the nutrient and phytochemical contents in novel hybrids maize [26]. To the best of our knowledge, this is the first study that compared nutritional and nutraceutical kernel compositions based on tolerance to $\mathrm{Al}$ [12]. Although previous studies have emphasized the quantification of phenolic acids content in plant roots $[27,28]$, our study is mainly focused on the kernel phenolic content. In future studies, a precise evaluation 
of the effect of $\mathrm{Al}$ concentration on PA profile in maize kernels should be the main focus. Furthermore, the impact of different acidic soils on the phytochemicals of Al-T kernels and the pathways involved should be investigated.

\section{Materials and Methods}

\subsection{Chemical and Reagents}

$\mathrm{NaOH}$ (Cat. 221465), $\mathrm{HCl}$ (Cat. 320331), ethyl acetate (Cat. 270989), $\mathrm{H}_{2} \mathrm{O}_{2}$ (Cat. 216763), ethanol (Cat. 32221), 2,2'-azo-bis(2-amidinopropane) dihydrochloride (AAPH) (Cat. 440914) and ( \pm )-6-hydroxy-2,5,7,8-tetramethylchromane-2-carboxylic acid (Trolox) (Cat. 238813) were purchased from Sigma-Aldrich (St. Louis, MO, USA). Gibco ${ }^{\circledR}$ phosphate buffer (PBS), pH 7.4 (Cat. 10010) was procured from ThermoFisher Scientific (Waltham, MA, USA).

\subsection{Maize Germplasm}

Sixteen inbred lines were used in this study in order to test possible parents to produce hybrids. Kernels of Al-T and Al-susceptible (Al-S) maize (Zea mays L.) were kindly provided by CIMMYT Maize Program. The Al-T maize inbred lines used were CLA161, CLA309, CLA37, CLA307, CLA44, and CLA84, whereas DTPWC9, LaPostaSeq, CML311-B, CLA35, P390am, and DTPWC9 were selected as Al-S maize inbred lines. The lines were previously screened and selected under aluminum soils conditions (Al toxicity, 60 to $300 \mu \mathrm{g}$ per liter of water in soil) in Cali Colombia where a 'hot spot' is located for soil acidity [29]. All analyses were performed by triplicate in two independent experiments.

\subsection{Determination of Morphological Parameters}

Thousand-kernel weight was determined by weighing 1000 kernels at $13 \%$ of grain moisture. Endosperm vitreousness was measured by estimating the relative proportion of vitreous endosperm area. Kernel hardness was determined on $100 \mathrm{~g}$ samples using the floaters test. The pericarp, endosperm, germ, and tip cap were manually dissected as described by [30], while kernel dimensions (thickness, width, and length) were obtained using a digital micrometer (Mitutoyo IP-65, Osaka, Japan).

\subsection{Proximate Analysis}

The dissected and separated anatomical parts (pericarp, endosperm, and germ) were assayed for proximate analysis. Crude protein, total starch, oil, crude fibre, and ash contents were determined according to the methods provided by the American Association of Cereal Chemists, including methods 44-15A, 46-12.01, 76-11, 32-10, and 08-12 [31].

\subsection{Extraction of Free and Bound Phenolic Acids}

Phenolics were extracted according to the method described by [30]. In brief, $1 \mathrm{~g}$ of finely ground maize kernels was mixed with $10 \mathrm{~mL}$ of ethanol $(80 \% \mathrm{v} / \mathrm{v})$ for $10 \mathrm{~min}$ at $50 \mathrm{rpm}$ in a shaker. Afterwards, the mixtures were centrifuged at $2500 \mathrm{rpm}$ and $18{ }^{\circ} \mathrm{C}$ for $10 \mathrm{~min}$. The resulting supernatants containing FPA were concentrated. The pellets were digested in $10 \mathrm{~mL}$ of $2 \mathrm{M} \mathrm{NaOH}$ at $23^{\circ} \mathrm{C}$ for $1 \mathrm{~h}$ with agitation under $\mathrm{N}_{2}$ gas. Next, the mixtures were neutralised with $0.5 \mathrm{~N} \mathrm{HCl}$. The final solution was evaporated to dryness and was further dissolved in $10 \mathrm{~mL}$ of water. Phenolic extracts were stored at $-20^{\circ} \mathrm{C}$ until further analysis.

\subsection{Determination of Total Phenolics}

Total phenolic acids were determined according to the method of Folin-Ciocalteu [30]. In brief, $500 \mu \mathrm{L}$ of FPA or CPA extracts were treated with $300 \mu \mathrm{L}$ of $1.5 \mathrm{M} \mathrm{H}_{2} \mathrm{O}_{2}$ and assayed using the Folin-Ciocalteu assay. The samples were quantified by spectrophotometry at $765 \mathrm{~nm}$ using a micro-plate reader (Epoch, BioTek Instruments, Inc., Winooski, VT, USA). The concentrations of total phenolic acids were expressed as $\mathrm{mg}$ of gallic acid equivalents (GAE) per $100 \mathrm{~g}$ (GAE/100 g of dry sample weight). 


\subsection{Antioxidant Capacity}

Antioxidant capacity (AOX) was determined by an oxygen radical absorbance capacity (ORAC) assay [30]. Extracts were evaluated against a standard of Trolox using Fluorescein as a probe. Peroxyl radicals were generated by 2,2'-azobis (2-amidinopropane) dihydrochloride and fluorescent loss was monitored in a spectrophotometer micro-plate reader (SynergyTM HT Multi-Detection, BioTek, Inc., Winooski, VT, USA). The absorbance of excitation and emission was set at 485 and $538 \mathrm{~nm}$, respectively. Data were expressed as Trolox equivalents (TEg-1 of dry sample weight).

\subsection{Statistical Analysis}

All analyses were performed by triplicate in two independent experiments. Data were presented as mean \pm standard error of mean and subjected to unpaired Student's $t$-test, considering $p<0.05$ as the level of significance. All statistical analysis was performed using Statistix v.8 (Analytical Soft, Tallahassee, FL, USA).

\section{Conclusions}

In summary, the nutritional and phytochemicals of the anatomical constituents of Al-T maize kernels were compared with their susceptible counterparts. An association between the $\mathrm{Al}$ tolerance mechanism and the increase in the contents of macronutrients and PAs was principally found in the germ structure. In addition, an increase in AOX was found in the Al-T kernels, which was also related to a higher concentration of PA in cell wall-bound extracts. The evidence provided herein establishes the possibility of utilizing Al-T maize lines to produce hybrids that could grow in acidic soils. In future studies, a precise evaluation of the impact of different acidic soils on the nutraceutical composition of Al-T kernels and the pathways involved should be investigated.

Finally, the results herein this imply that the hybrids generated using Al-T maize inbred lines are an attractive source of nutrients and phytochemicals in farming regions containing acid soils.

Author Contributions: All authors contributed to the study conception and design. Material preparation, data collection and analysis were performed by S.O.-I. The first draft of the manuscript was written by S.G.-L. and S.O.-I. and S.S.-S. commented on previous versions of the manuscript. All authors read and approved the final manuscript.

Funding: This research received no external funding. All founds were provided by the AgroBio Unit of Tecnologico de Monterrey.

Institutional Review Board Statement: Not applicable.

Informed Consent Statement: Not applicable.

Data Availability Statement: The datasets generated during and/or analyzed during the current study are available from the corresponding author on reasonable request.

Acknowledgments: We thank Luis Alberto Narro-León and Natalia Palacios-Rojas from CIMMYT for donating the maize samples used for this study.

Conflicts of Interest: The authors declare no conflict of interest.

\section{References}

1. FAO. Crop Prospects and Food Situation. Available online: http://www.fao.org/giews/reports/crop-prospects/en/ (accessed on 15 September 2021).

2. Barrera-Arellano, D.; Badan-Ribeiro, A.P.; Serna-Saldivar, S.O. Corn oil: Composition, processing and utilization. In Corn: Chemistry and Technology; Serna-Saldivar, S.O., Ed.; AACC-International: St. Paul, MN, USA, 2019; pp. 593-614.

3. Rao, I.M.; Zeigler, R.S.; Vera, R.; Sarkarung, S. Selection and breeding for acid-soil tolerance in crops. Bioscience 1993, 43, 454-465. [CrossRef]

4. Panda, S.K.; Baluska, F.; Matsumoto, H. Aluminium stress signalling in plants. Plant Signal Behav. 2009, 4, 592-597. [CrossRef]

5. Maron, L.G.; Kirst, M.; Mao, C.; Milner, M.J.; Menossi, M.; Kochian, L.V. Transcriptional profiling of aluminum toxicity and tolerance responses in maize roots. New Phytol. 2008, 179, 116-128. [CrossRef] [PubMed] 
6. Matonyei, T.K.; Cheprot, R.K.; Liu, J.; Piñeros, M.A.; Shaff, J.E.; Gudu, S. Physiological and molecular analysis of aluminum tolerance in selected Kenyan maize lines. Plant Soil. 2014, 377, 357-367. [CrossRef]

7. Poschenrieder, C.; Gunsé, B.; Corrales, I.; Barceló, J. A glance into aluminium toxicity and resistance in plants. Sci. Total Environ. 2008, 400, 356-368. [CrossRef]

8. Von Uexküll, H.R.; Mutert, E. Global extent, development and economic impact of acid soils. Plant Soil. 1995, 171, 1-15. [CrossRef]

9. Duque-Vargas, J.; Pandey, S.; Granados, G.; Ceballos, H.; Knapp, E. Inheritance of tolerance to soil acidity in tropical maize. Crop Sci. 1994, 34, 50-54. [CrossRef]

10. Khan, A.A.; McNeilly, T. Variability in aluminium and manganese tolerance among maize accessions. Genet. Resour. Crop Evol. 1998, 45, 525-531. [CrossRef]

11. Ngoune, T.L.; Mutengwa, C.S.; Ngonkeu, E.L.M.; Gracen, V. Breeding maize for tolerance to acidic soils: A review. Agronomy 2018, 8, 84. [CrossRef]

12. Kochian, L.V.; Hoekenga, O.A.; Magalhaes, J.V.; Piñeros, M.A. Maize Al tolerance. In Handbook of Maize: Its Biology; Bennetzen, J.L., Hake, S.C., Eds.; Springer: New York, NY, USA, 2009; pp. 367-380.

13. Nuss, E.T.; Tanumihardjo, S.A. Maize: A paramount staple crop in the context of global nutrition. Compr. Rev. Food Sci. Food Saf. 2010, 9, 417-436. [CrossRef] [PubMed]

14. García-Lara, S.; Chuck-hernandez, C.; Serna-Saldivar, S.O. Development and structure of the corn kernel. In Corn: Chemistry and Technology; Serna-Saldivar, S.O., Ed.; AACC-International: St. Paul, MN, USA, 2019; pp. 147-163.

15. Veloso, M.; Leão De Castro, M.; Mendonça, A.L.; Santos, G.G.; Silva, M.S. Corn germ with pericarp in relation to whole corn: Nutrient contents, food and protein efficiency, and protein digestibility-corrected amino acid score. Food Sci. Technol. 2011, 31, 264-269.

16. Ofei-Manu, P.; Wagatsuma, T.; Ishikawa, S.; Tawaraya, K. The plasma membrane strength of the root-tip cells and root phenolic compounds are correlated with Al tolerance in several common woody plants. Soil Sci. Plant Nutr. 2001, 47, 359-375. [CrossRef]

17. Tolrà, R.P.; Poschenrieder, C.; Luppi, B.; Barceló, J. Aluminium-induced changes in the profiles of both organic acids and phenolic substances underlie Al tolerance in Rumex acetosa L. Environ. Exp. Bot. 2005, 54, 231-238. [CrossRef]

18. Ryan, P.; Delhaize, P.; Jones, D. Function and mechanism of organic anion exudation from plant roots. Annu. Rev. Plant Physiol. Plant Mol. Biol. 2001, 52, 527-560. [CrossRef] [PubMed]

19. Kidd, P.S.; Llugany, M.; Poschenrieder, C.; Gunsé, B.; Barceló, J. The role of root exudates in aluminium resistance and siliconinduced amelioration of aluminium toxicity in three varieties of maize (Zea mays L.). J. Exp. Bot. 2001, 52, 1339-1352. [PubMed]

20. Kochian, L.V.; Hoekenga, O.A.; Piñeros, M.A. How do crop plants tolerate acid soils? Mechanisms of aluminum tolerance and phosphorous efficiency. Annu. Rev. Plant Biol. 2004, 55, 459-493. [CrossRef]

21. Giannakoula, A.; Moustakas, M.; Syros, T.; Yupsanis, T. Aluminium stress induces up-regulation of an efficient antioxidant system in the Al-tolerant maize line but not in the Al-sensitive line. Environ. Exp. Bot. 2010, 67, 487-494. [CrossRef]

22. Ribeiro, C.; Cambraia, J.; Peixoto, P.H.P.; Meira, É.; Fonseca, D., Jr. Antioxidant system response induced by aluminium in two rice cultivars. Braz. J. Plant Physiol. 2012, 24, 107-116. [CrossRef]

23. Du, H.; Huang, Y.; Qu, M.; Li, Y.; Hu, X.; Yang, W. A maize ZmAT6 gene confers aluminium tolerance via reactive oxygen species scavenging. Front. Plant Sci. 2020, 11, 1016-1021. [CrossRef]

24. Yan, L.; Riaz, M.; Liu, J.; Yu, M.; Cuncang, J. The aluminum tolerance and detoxification mechanisms in plants; recent advances and prospects. Crit. Rev. Environ. Sci. Technol. 2021, 1-37. [CrossRef]

25. Boscolo, P.R.S.; Menossi, M.; Jorge, R.A. Aluminium-induced oxidative stress in maize. Phytochemistry 2003, 62, 181-189. [CrossRef]

26. Xu, L.M.; Liu, C.; Cui, B.M.; Wang, N.; Zhao, Z.; Zhou, L.-N.; Huang, K.-F.; Ding, J.-Z.; Du, H.-M.; Jiang, W.; et al. Transcriptomic responses to aluminium (Al) stress in maize. J. Integr. Agric. 2018, 17, 1946-1958. [CrossRef]

27. Tolrà, R.; Barceló, J.; Poschenrieder, C. Constitutive and aluminium-induced patterns of phenolic compounds in two maize varieties differing in aluminium tolerance. J. Inorg. Biochem. 2009, 103, 1486-1490. [CrossRef]

28. Mapiemfu-Lamaré, D.; Ndindeng, S.A.; Ngome, A.F.; Thé, C.; Tsoata, E.; Zonkeng, C.; Mfopou, M.C.; Bihnchang, L.; Etame, F. Early Criterion to Screen Maize Varieties for Their Tolerance to Aluminium Toxic Soil. Int. J. Agric. For. 2012, 2, 161-165. [CrossRef]

29. Narro, L.A.; Arcos, A.L. Genetics of aluminium-induced callose formation in maize roots, a selection trait for aluminium resistance. Crop Sci. 2010, 50, 1848-1853. [CrossRef]

30. García-Lara, S.; Bergvinson, D.J. Phytochemical and nutraceutical changes during recurrent selection for storage pest resistance in tropical maize. Crop Sci. 2014, 54, 2423-2432. [CrossRef]

31. American Association of Cereal Chemists. Approved Methods of the American Association of Cereal Chemists, 10th ed.; AACC: St. Paul, MN, USA, 2000; p. 450. 